\title{
Cyanoacrylate tissue glue for wound repair in early posttrabeculectomy conjunctival bleb leak: a case series
}

\author{
Abdul-Rahim Haslinda \\ Yaakub Azhany \\ Rasid Noor-Khairul \\ Embong Zunaina \\ Ahmad-Tajudin Liza- \\ Sharmini
}

Department of Ophthalmology, School of Medical Sciences, Health Campus, Universiti Sains Malaysia, Kubang Kerian, Kelantan, Malaysia

Correspondence: Yaakub Azhany Department of Ophthalmology, School of Medical Sciences, Health Campus, Universiti Sains Malaysia, 16150 Kubang Kerian, Kelantan, Malaysia

Tel +60 I 97676362

Fax +60 I 97653370

Email azhany@usm.my
This article was published in the following Dove Press journal:

International Medical Case Reports Journal

22 July 2015

Number of times this article has been viewed

\begin{abstract}
We demonstrated a noninvasive management of early bleb leak following trabeculectomy using cyanoacrylate tissue glue (CATG). Three patients who underwent augmented trabeculectomy with mitomycin C with early bleb leak between January 2009 and June 2010 were reviewed. Case 1 and Case 2 exhibited bleb leak on postoperative Day 1 and Case 3 showed leak on follow-up at postoperative Day 7. Case 1 was successfully sealed with CATG at postoperative Day 3, after failed pressure padding and bandage contact lens. Case 2 was successfully sealed with CATG at postoperative Day 3 , after failed pressure padding and conjunctiva flap resuturing. In Case 3, the leaking conjunctival flap was managed with combined techniques of resuturing and applying CATG at postoperative Day 9, after failed pressure padding. During leakage, the intraocular pressure was low $(6-8 \mathrm{mmHg})$ in all three cases, with shallow anterior chamber depth and absence of other complications such as choroidal detachment, hypotony maculopathy, or endophthalmitis. Foreign body sensation was the main complaint following the procedure. No clinical allergy reaction was documented. CATG may serve as a potential adjunctive and effective method in the management of posttrabeculectomy early bleb leak.
\end{abstract}

Keywords: cyanoacrylate tissue glue, bleb leak, trabeculectomy, mitomycin C

\section{Introduction}

Trabeculectomy is a surgical glaucoma procedure that aims to lower the intraocular pressure (IOP) by creating a fistula for aqueous drainage from the anterior chamber to the subtenon space. Lower IOP will prevent further insult to the optic nerve and hence further visual field loss. Mitomycin C (MMC) is commonly used as adjunctive treatment in trabeculectomy in order to increase the survival of filtering bleb. However, MMC also increases the incidence of bleb leak. Bleb leakage that occurs within the first 1 month following trabeculectomy is considered an early postoperative leak, and it is frequently encountered as an unfortunate complication. ${ }^{1}$ Its incidence varies from $0 \%$ to $30 \% .^{2}$ The bleb leak may be self-limiting or complicated with a shallow and flat anterior chamber, cataract formation, choroidal detachment, and hypotony maculopathy. ${ }^{3}$ Risk of bleb-related infection increases up to 26-fold following bleb leakage. ${ }^{4}$

Conservative measures and medical approaches are practiced prior to consideration of surgical retreatment in bleb leak cases. These include pressure patching, bandage soft contact lens, collagen shield, sclera shell tamponade, aqueous suppressants, compression suture, conjunctiva suturing, trichloroacetic acid, and autologous blood injection. ${ }^{5}$ For decades, surgical repair or wound revision has been a gold standard in the management of leaking bleb. The application of tissue adhesive has been widely 
accepted as a suture alternative in recent times. The use of cyanoacrylate tissue glue (CATG) has been successfully reported in ophthalmology literatures, ranging from sealing corneal perforations to closure of retinal breaks and reattachment of retina in retinal detachment cases. ${ }^{6}$

Cyanoacrylate belongs to a family of polymers. The liquid form of cyanoacrylate consists of monomers of cyanoacrylate molecules, with clear colorless appearance and strong odor. The ester form of cyanoacrylate, $N$-butyl-2-cyanoacrylate, is one of the adhesive components that have been widely used in medical and veterinary applications. ${ }^{7}$ Cyanoacrylate liquid monomers rapidly solidify by polymerization and form a firm adhesive bond when coming into contact with weak base, releasing a little heat, as well as in presence of ionic substances such as moisture, blood, or tissue fluids. ${ }^{7}$ In polymerized form, the tensile strength of bonding of these polymers has been observed to be the highest among all glues. It also has bacteriostatic property. ${ }^{8}$ Another alternative group of adhesives available include biological fibrin glue (a blood-derived product), gelatin and thrombin products, albumin and glutaraldehyde products, as well as polyethylene glycol polymers. ${ }^{9}$

We reported three successfully sealed early bleb leak cases with CATG. We have used GluStitch ${ }^{\circledR}$, an N-butyl-2cyanoacrylate tissue adhesive type.

\section{Case series}

We retrospectively analyzed the outcome of three patients with early leaking filtering blebs managed with CATG. We reviewed the medical records of three patients who underwent augmented trabeculectomy with MMC with early bleb leak between January 2009 and June 2010 at the Hospital Universiti Sains, Malaysia. Approval from the local medical ethic committee was obtained. All patients gave informed consent and their anonymity was preserved.
Two cases had bleb leakage at postoperative Day 1, and bleb leakage was detected at postoperative Day 7 in one case. The diagnosis of bleb leaks was confirmed by a positive Seidel's test, which also identified the leakage site. All bleb leakages were $<2 \mathrm{~mm}$ in size. They occurred either from the conjunctival flap buttonhole or along the suture track, which was located $>2 \mathrm{~mm}$ from the limbus. The leak was complicated with low IOP of $<10 \mathrm{mmHg}$ and shallow anterior chamber depth but without iridocorneal touch. Other complications, such as choroidal detachment, hypotony maculopathy, or endophthalmitis, were absent in all cases. The patients retained their preoperative visual acuity.

An individualized approach was used in every case. The first line of management was conservative, which consisted of pressure padding, bandaged contact lens, and aqueous suppression. In the first case, CATG was used along with a plastic disk after 2 days of failed pressure bandage management. In the second case, CATG alone was used after 2 days' failed conservative management and subsequent surgical procedure, while in the third case, CATG was used in combination with surgical procedure after 2 days' failed pressure bandage management. A summary of cases and outcomes is shown in Table 1.

All patients underwent application of CATG under topical anesthesia of proparacaine $0.5 \%$ or subconjunctival lignocaine $2 \%$. To facilitate instillation of CATG, $0.1 \mathrm{~mL}$ of CATG was filled in a $1 \mathrm{~mL}$ tuberculin syringe mounted with a $30 \mathrm{G}$ needle. A drop of CATG was approximately equivalent to $0.05 \mathrm{~mL}$. A plastic disk was used in one of the cases (Case 1). It was a modified disk of $4 \mathrm{~mm}$ diameter, cut from sterile soft clear plastic cover of a butterfly needle using straight scissors. The leakage sites were dried using dry cotton applicator.

Postgluing, they received topical eyedrops of prednisolone acetate 1\% 4-hourly per day, ciprofloxacin 2-hourly

Table I Summary of cases and outcomes

\begin{tabular}{|c|c|c|c|c|c|c|c|}
\hline Case & $\begin{array}{l}\text { Age, sex, } \\
\text { and type of } \\
\text { glaucoma }\end{array}$ & $\begin{array}{l}\text { Onset of } \\
\text { bleb leak }\end{array}$ & $\begin{array}{l}\text { Initial failed } \\
\text { methods }\end{array}$ & $\begin{array}{l}\text { Application } \\
\text { method of CATG/ } \\
\text { time of treatment }\end{array}$ & $\begin{array}{l}\text { IOP during } \\
\text { bleb leak } \\
\text { (mmHg) }\end{array}$ & $\begin{array}{l}\text { IOP postgluing } \\
(\mathrm{mmHg})\end{array}$ & Outcomes \\
\hline I & 57 y/o, M, NVG & Postop Day I & $\begin{array}{l}\text { Pressure padding, } \\
\text { bandage contact lens }\end{array}$ & $\begin{array}{l}\text { CATG with plastic } \\
\text { disk/postop Day } 3\end{array}$ & 8 & 18 & Success \\
\hline 2 & 63 y/o, M, NVG & Postop Day I & $\begin{array}{l}\text { Pressure padding, } \\
\text { aqueous suppression, } \\
\text { resuturing }\end{array}$ & $\begin{array}{l}\text { CATG alone/postop } \\
\text { Day } 3\end{array}$ & 7 & 12 & Success \\
\hline 3 & 81 y/o, F, POAG & Postop Day 7 & Pressure padding & $\begin{array}{l}\text { CATG with } \\
\text { resuturing/postop } \\
\text { Day } 10\end{array}$ & Undetectable & 10 & Success \\
\hline
\end{tabular}

Abbreviations: CATG, cyanoacrylate tissue glue; F, female; IOP, intraocular pressure; M, male; NVG, neovascular glaucoma; postop, postoperative; POAG, primary openangle glaucoma; y/o, years old. 
per day, and homatropine $1 \%$ twice daily for 2 weeks. At 2 weeks, both prednisolone acetate $1 \%$ and ciprofloxacin were tapered to four times per day for another 2 weeks, while homatropine was stopped. At 4 weeks, ciprofloxacin was stopped and prednisolone acetate $1 \%$ was used four times daily for a further period of 2-3 months. Patients were followed up weekly after gluing for 1 month, and then subsequent monthly reviews were undertaken. During clinic visits, blebs were diffusely formed with no recurrent leak in all cases. No incidence of blebitis or endophthalmitis was found at the 3-month follow-up.

\section{Case I}

A 57-year-old male with right eye neovascular glaucoma secondary to branch retinal vein occlusion underwent right eye augmented trabeculectomy. He developed filtering bleb leak on Day 1 of the postoperative period. On ocular examination, there was presence of shallow bleb, with a positive Seidel test seen at the nasal part of the bleb. The anterior chamber was shallow and IOP with applanation tonometry was $8 \mathrm{mmHg}$. The eye was managed with pressure padding and bandaged contact lens for 2 days. Examination on following day revealed persistent slow bleb leak from a similar site (Figure 1). Sealing of the leaking bleb with CATG with plastic disk was done at postoperative Day 3 under slit lamp. The patient was first seated, and then the identified bleb leakage site was dried. One drop of CATG was applied (Figure 2), and a plastic disk was placed on top (Figure 3). It was allowed to crystallize for 5 minutes. The site was again checked with fluorescein sodium strip, and no sign of leakage was observed (Figure 4). Eye examination on Day 1 postgluing showed negative Seidel test, clear cornea, and deepened anterior chamber with IOP $18 \mathrm{mmHg}$.

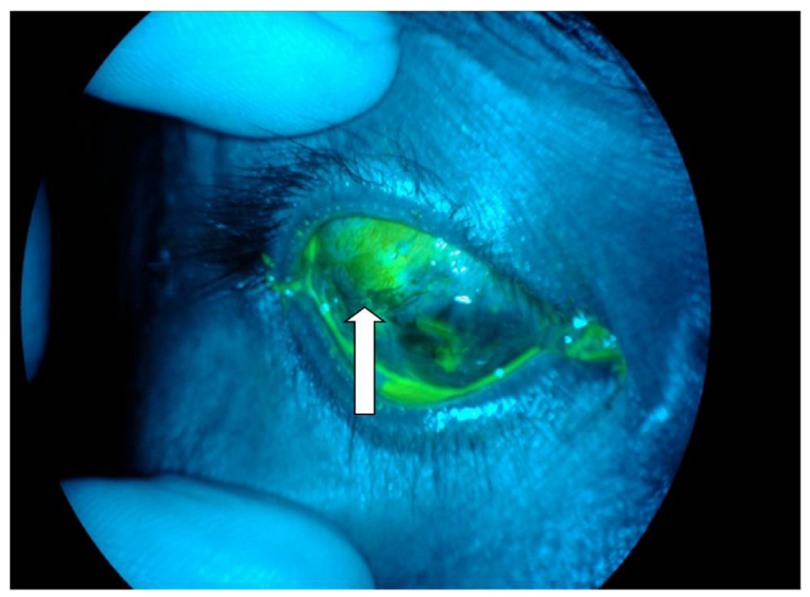

Figure I Leaking bleb with Siedel test positive (arrow) in Case I.

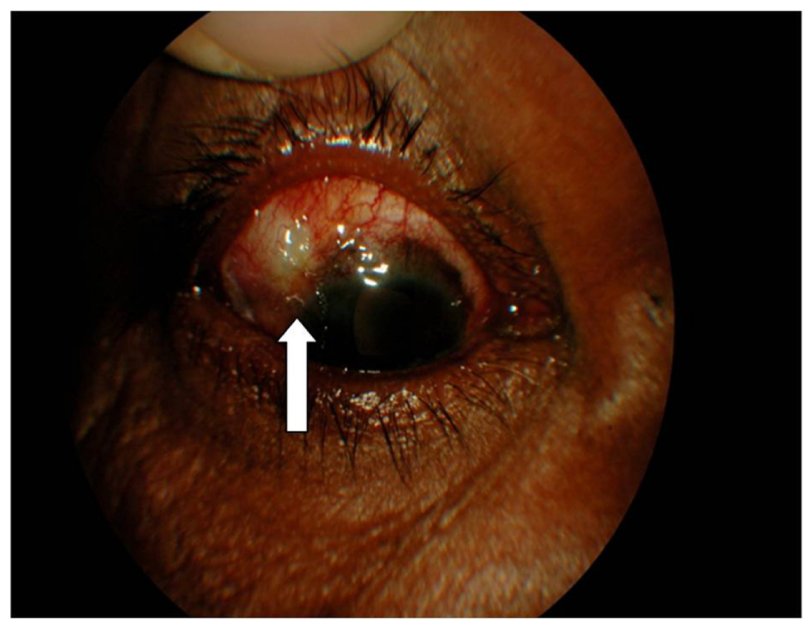

Figure 2 Application of cyanoacrylate tissue glue (arrow) in Case I.

He complained of mild foreign body sensation postgluing. Two weeks later, the plastic disk glue became dislodged with no subsequent ocular complication. Follow-up at 3 months showed well-sealed bleb and no recurrent leak, with IOP of $19 \mathrm{mmHg}$.

\section{Case 2}

A 63-year-old male underwent left eye augmented trabeculectomy surgery in January 2009 for refractory secondary glaucoma after failed initial nonaugmented trabeculectomy. He developed filtering bleb leak on Day 1 of the postoperative period. On ocular examination, there was presence of shallow bleb with positive Seidel test at the temporal part of the bleb. The anterior chamber was shallow and IOP with applanation tonometry was $6 \mathrm{mmHg}$. The eye was managed with pressure padding and aqueous suppression. The next day, there was persistent leaking. Conjunctival flap resuturing was performed. On postoperative Day 3, the bleb showed

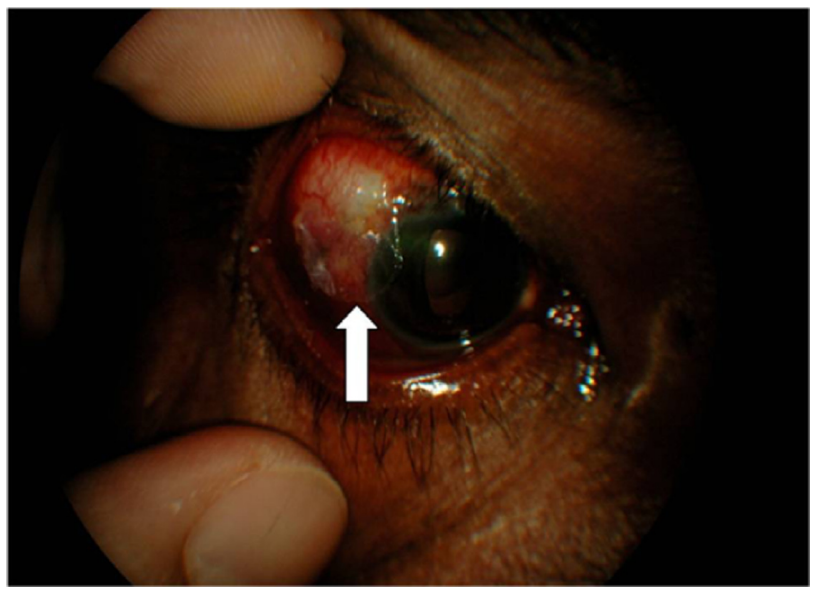

Figure 3 Plastic disk applied on top of cyanoacrylate tissue glue (arrow) in Case I. 


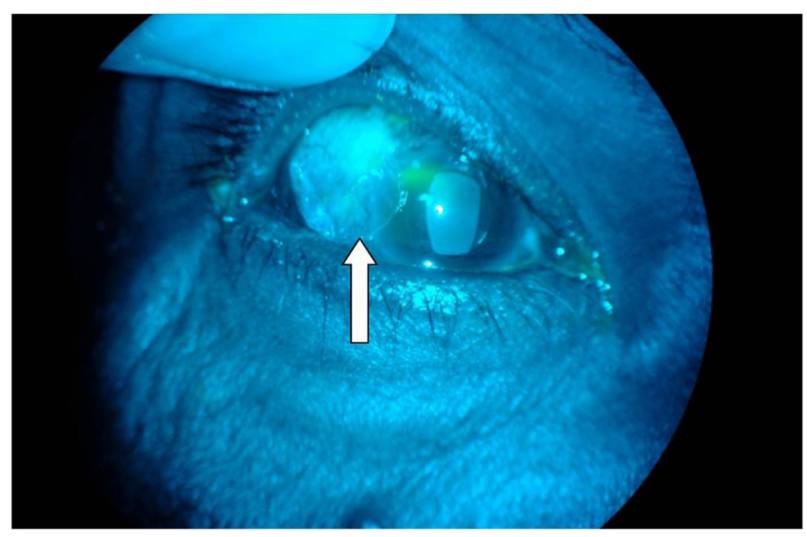

Figure 4 Sealed leaking bleb with Siedel negative result.

Note: Plastic disk in situ (arrow) is surrounded by crystallized cyanoacrylate tissue glue in Case I.

leakage again from the similar site with IOP of $7 \mathrm{mmHg}$. Sealing of the leaking bleb with CATG was done on the same day. As the patient was laid supine, an eye speculum was placed to prevent blinking. The identified leakage site was then dried. One drop of CATG was applied and left to crystallize for 5 minutes. The glued site was checked with fluorescein strip, and no sign of leakage was observed. Eye examination on Day 1 postgluing revealed negative Seidel test, clear cornea, and anterior chamber deepened, with IOP of $12 \mathrm{mmHg}$. He complained of mild foreign body sensation for the subsequent 1 week, which was tolerable with minimal irritation. The final follow-up was at 3 months after the procedure: the filtering bleb was Siedel negative and the IOP was maintained below $15 \mathrm{mmHg}$. The patient then defaulted on follow-up.

\section{Case 3}

An 81-year-old female, a case of advanced primary openangle glaucoma of both eyes, underwent left eye augmented trabeculectomy in March 2009. She developed filtering bleb leak on Day 7 of the postoperative period. On ocular examination, there was presence of bleb leak with positive Seidel test near the limbus. The anterior chamber was shallow and IOP with applanation tonometry was undetectable. The eye was managed with pressure padding for 2 days. Examination on the following day revealed persistent slow bleb leak from similar site. As the bleb was persistently leaking, she underwent the combined techniques of resuturing and applying CATG at postoperative Day 10. In the supine position, the eye speculum was placed. The identified leakage site of the conjunctival flap was first resutured. The site was then dried. One drop of CATG was applied, and it was left to crystallize for 5 minutes. The sutured and glued site was checked with fluorescein strip, and there was no sign of leakage. Eye examination on Day 1 postgluing showed that the Seidel test was negative, cornea was clear, and the anterior chamber deepened, with IOP of $10 \mathrm{mmHg}$. There was complaint of mild foreign body sensation postgluing for 3 weeks; however, no severe irritation was noted. At the 3-month follow-up, the bleb remained Siedel negative, with the IOP slightly increased to $15 \mathrm{mmHg}$.

\section{Discussion}

Managing bleb leaks often pose a challenge upon failing both conservative approach and surgical repair. The incidence of postoperative bleb leakage after trabeculectomy was reported to reach up to $56 \%,{ }^{10}$ in which higher risk was anticipated with the use of augmenting metabolites. ${ }^{11}$ The wide use of MMC as adjunctive therapy during trabeculectomy was found to be a cause for delayed bleb leaks. ${ }^{12}$ Meanwhile, early bleb leaks, which comprise wound leak and conjunctival buttonholes, are likely to be contributed by fluctuations and changes in tissue swelling during the postoperative period, cutting through of sutures, or changes in wound apposition caused by blinking or eye rubbing, apart from deficient wound closure, patent stitch tracts, and surgically traumatized conjunctiva. ${ }^{13}$ Despite that, early bleb leak is not a poor prognostic indicator for intermediate bleb survival and IOP control in patients undergoing MMC trabeculectomy, as proved by Alwitry et al. ${ }^{1}$ Longer follow-up of $>1$ year is necessary to further determine the relationship between early bleb leak and longterm bleb survival.

Cyanoacrylate is used in managing bleb leaks and the glue has the advantage of biocompatibility, which allows application over the ocular surface with minimal toxicity while promoting and facilitating rapid reepithelialization. ${ }^{14}$ Successful closure of leaking blebs with cyanoacrylate adhesive in studied cases was achieved either using the glue alone or in combination with other conservative methods, such as pressure patching, bandage soft contact lens, Simmons shell, aqueous suppressant, autologous blood, and dye-enhanced argon laser photocoagulation. ${ }^{15-17}$ Several applications of the tissue adhesives, however, may be required to ensure favorable outcome, as reported by Okabe et al. ${ }^{18}$ However, unsuccessful results have also been reported with the tissue glue. Mandal ${ }^{19}$ attempted cyanoacrylate in four out of seven cases with late bleb leak but found them unsuccessful.

There were significant differences between these studies and our study. Most of the previously reported bleb leaks were of late-onset occurrence, and the majority of studies did not specify the size of the leak. In our cases, all three were 
Table 2 Case summaries of literature review

\begin{tabular}{|c|c|c|c|c|c|c|c|c|c|c|}
\hline \multirow[t]{3}{*}{ Authors } & \multirow[t]{3}{*}{ Total } & \multirow{3}{*}{$\begin{array}{l}\text { Onset of bleb } \\
\text { leak }\end{array}$} & \multicolumn{7}{|c|}{ Management of bleb leak } & \multirow{3}{*}{$\begin{array}{l}\text { Complications } \\
\text { observed }\end{array}$} \\
\hline & & & \multicolumn{3}{|c|}{ CATG alone } & \multicolumn{3}{|c|}{$\begin{array}{l}\text { Combined CATG } \\
\text { and other methods }\end{array}$} & \multirow{2}{*}{$\begin{array}{l}\begin{array}{l}\text { Other } \\
\text { methods }\end{array} \\
\text { Total }\end{array}$} & \\
\hline & & & Total & Success & Failure & Total & Success & Failure & & \\
\hline Zalta and Weider ${ }^{15}$ & $5^{*}$ & 10 months -20 years & $\mathrm{I}$ & 1 & 0 & 4 & 4 & 0 & - & Corneal abrasion \\
\hline Wilensky $^{16}$ & $12 *$ & 6 months -20 years & - & - & - & 2 & 2 & 0 & $10^{\alpha}$ & $\mathrm{N} / \mathrm{A}$ \\
\hline Euswas et $\mathrm{al}^{17}$ & $7^{*}$ & Late onset & - & - & - & 2 & 2 & 0 & $5^{\alpha}$ & N/A \\
\hline Okabe et $a^{18}$ & $2 *$ & Late onset & - & - & - & 2 & 2 & 0 & - & $N / A$ \\
\hline Mandal $^{19}$ & $7 *$ & 1.5 years -16 years & - & - & - & 4 & 0 & 4 & $7^{\alpha}$ & $\mathrm{N} / \mathrm{A}$ \\
\hline Our series & $3^{*}$ & $<2$ weeks & I & I & 0 & 2 & 2 & 0 & - & Foreign body sensation \\
\hline
\end{tabular}

Notes: *Cases managed with glue were included; ${ }^{\alpha}$ other methods of management of bleb leak also included.

Abbreviations: CATG, cyanoacrylate tissue glue; N/A, not available.

detected very early within a week posttrabeculectomy, which was augmented with MMC. This is in agreement with the study conducted by Alwitry et al, ${ }^{1}$ which found that the time of detection of early bleb leak ranges from 1 day to 21 days in MMC trabeculectomy patients. The size of the leak was small in all of our cases, permitting the use of CATG.

There was no impending vision-threatening complication setting in upon the onset. We considered that premature intervention without hypotony maculopathy or choroidal detachment was reasonable after adequate trial of conservative postoperative care being undertaken. Cyanoacrylate adhesive was however not our first line of bleb leak management. The glue was attempted after failed initial conservative and/or surgical method in all of our cases. From our three cases, it seemed that the CATG was responsible for sealing the bleb leaks. However, we admit that we are not too certain that the glue alone contributed to the effective seal of the bleb leaks as many of early leaks seal spontaneously. In the more complicated Case 3, in which gluing was undertaken but in combination with resuturing, again the success cannot be attributed solely to the glue.

From a comparison of literature review and our cases, we observed that CATG could effectively be used as adjunct, rather than primary treatment, to seal an early bleb leak of size $2 \mathrm{~mm}$ or less. CATG is not apparently suitable for thin avascular blebs with late-developing leaks. Case summaries of literature review are illustrated in Table 2.

The advantages of CATG in the management of early bleb leakage in our cases are as follows: 1) clinically no toxic effect on vascular tissue, 2) strong and rapid bonding, 3) good adherence to conjunctiva, 4) ability to bond in the presence of small amount of blood and tears, 5) possible bacteriotoxicity, 6) water-tight, sutureless closure, and 7) accessible, affordable, fast, safe, simple, and relative ease of application.
There are a few insignificant limitations over its use that have been addressed: 1) big presterilized glue container tip, making it difficult to specify and localize to the desired site; 2) excessive liquidic properties, causing it to diffuse to other undesired surrounding sites while waiting for it to solidify; 3) formation of a solid, impermeable mass in situ, which persists as a foreign body, thus giving rise to foreign body sensation; 4) impermeability to fluids and metabolites; and 5) risk of development of severe peribleb inflammation around both the glue and the plastic disk in the weeks after gluing, before the glue ultimately naturally dislodges.

\section{Conclusion}

CATG may serve as one of the effective alternative adjunctive methods in the management of posttrabeculectomy early bleb leak. Nevertheless, further study of its use in various phases of bleb leak is required. Modification of product preparation of CATG for ophthalmic use will facilitate the usage.

\section{Disclosure}

The authors report no conflicts of interest in this work.

\section{References}

1. Alwitry A, Rotchford A, Patel V, Abedin A, Moodle J, King AJ. Early bleb leak after trabeculectomy and prognosis for bleb failure. Eye. 2009;23:858-863.

2. Henderson HW, Ezra E, Murdoch IE. Early postoperative trabeculectomy leakage: incidence incidence, time course, severity, and impact on surgical outcome. Br J Ophthalmol. 2004;88:626-629.

3. Edmunds B, Thompson JR, Salmon JF. The National Survey of Trabeculectomy III. Early and late complications. Eye. 2002;16: 297-303.

4. Soltau JB, Rothman RF, Budenz DL, et al. Risk factors for glaucoma filtering bleb infections. Arch Ophthalmol. 2000;118:338-342.

5. Scott DR, Quigley HA. Medical management of a high bleb phase after trabeculectomies. Ophthalmology. 1988;95:1169-1173.

6. Sinha R, Kumar C, Sharma N. Use of tissue adhesives in ophthalmology. Indian J Ophthalmol. 2009;57:409-413.

7. Lauto A, Mawad D, Foster R, John L. Review adhesive biomaterials for tissue reconstruction. J Chem Technol Biotechnol. 2008;83:464-472. 
8. Chen WL, Lin CT, Hsieh CY, Tu IH, Chen WY, Hu FR. Comparison of the bacteriostatic effects, corneal cytotoxicity, and the ability to seal corneal incisions among three different tissue adhesives. Cornea. 2007;26:1226-1234.

9. Panda A, Kumar S, Kumar A, Bansal R, Bhartiya S. Fibrin glue in ophthalmology. Indian J Ophthalmol. 2009;57:371-379.

10. Batterbury M, Wishart PK. Is high initial outflow of benefit in trabeculectomy? Eye. 1993;7:109-112.

11. Cohen JS, Greff LJ, Novack GD, Wind BE. A placebo-controlled, double-masked evaluation of mitomycin $\mathrm{C}$ in combined glaucoma and cataract procedures. Ophthalmology. 1996;103(11):1934-1942.

12. Anand N, Arora S, Clowes M. Mitomycin C augmented glaucoma surgery: evolution of filtering bleb avascularity, transconjunctival oozing, and leaks. Br J Ophthalmol. 2006;90(2):175-180.

13. Rand Allingham R, editor. Shields'Textbook of Glaucoma. 5th ed. Philadelphia: Lippincott Williams \& Wilkins; 2005.
14. Chan SM, Boisjoly H. Advances in the use of adhesives in ophthalmology. Curr Opin Ophthalmol. 2004;15(4):305-310.

15. Zalta HA, Weider HR. Closure of leaking filtering blebs with cyanoacrylate tissue adhesive. Br J Ophthalmol. 1991;75:170-173.

16. Wilensky JT. Management of late bleb leaks following glaucoma filtering surgery. Trans Am Ophthalmol Soc. 1992;90:161-170.

17. Euswas A, Warrasak S, Methasiri S. Sequential management of chronic leaking bleb. Asian J Ophthalmol. 2005;7:26-29.

18. Okabe M, Kitagawa K, Yoshida T, et al. Application of 2-octylcyanoacrylate for corneal perforation and glaucoma filtering bleb leak. Clin Ophthalmol. 2013;7:649-653.

19. Mandal AK. Management of the late leaking filtration blebs. A report of seven cases and a selective review of literature. Indian J Ophthalmol. 2001;49:247.
International Medical Case Reports Journal

\section{Publish your work in this journal}

The International Medical Case Reports Journal is an international, peer-reviewed open-access journal publishing original case reports from all medical specialties. Previously unpublished medical posters are also accepted relating to any area of clinical or preclinical science. Submissions should not normally exceed 2,000 words or

\section{Dovepress}

4 published pages including figures, diagrams and references. The manuscript management system is completely online and includes a very quick and fair peer-review system, which is all easy to use. Visit http://www.dovepress.com/testimonials.php to read real quotes from published authors.

Submit your manuscript here: http://www.dovepress.com/international-medical-case-reports-journal-journal 